\title{
MIR106B Pre-miRNA
}

National Cancer Institute

\section{Source}

National Cancer Institute. MIR106B Pre-miRNA. NCI Thesaurus. Code C82752.

MIR106B pre-miRNA is an oligoribonucleotide that is encoded by the human MIR106B gene and is involved in the regulation of gene expression. 